\title{
Uncertainty and perspectives in studies of atmospheric nitrogen deposition in China: A response to Liu et al. (2015)
}

\author{
Nianpeng He *, Jianxing Zhu, Qiufeng Wang \\ Key Laboratory of Ecosystem Network Observation and Modeling, Institute of Geographic Sciences and Natural Resources Research, Chinese Academy of Sciences, Beijing 100101, China
}

\section{A R T I C L E I N F O}

\section{Article history:}

Received 13 March 2015

Accepted 13 March 2015

Available online 25 March 2015

Editor: D. Barcelo

\section{Keywords:}

Nitrogen

Wet deposition

Spatial pattern

Composition

Influencing factors

\begin{abstract}
A B S T R A C T
In this paper, we have formally responded to the speculation in "Liu et al. suspect that Zhu et al. (2015) may have underestimated dissolved organic $\mathrm{N}$ but overestimated total particulate $\mathrm{N}$ in wet deposition in China" by Liu et al. (2015). Here, we first discussed the uncertainty and plausible reasons of atmospheric deposition in China, which have been reported in different studies. We disagree with their interpretation on some points. Firstly, the difficulties in quality control from sampling to analyzing are common to all studies regarding atmospheric deposition, including the studies cited by Liu et al. (2015). More importantly, their discussion did not fully consider the apparent influence of different scaling-up methods (from an observation site scale to a national scale) on estimations of atmospheric $\mathrm{N}$ deposition in China. Furthermore, we provided the optimal approaches to resolve these challenges discussed in order to promote the related studies of atmospheric $\mathrm{N}$ deposition in China in the future.
\end{abstract} (c) 2015 Elsevier B.V. All rights reserved.
The deposition of atmospheric nitrogen $(\mathrm{N})$ is integral to the global $\mathrm{N}$ cycle (Galloway et al., 2004). Anthropogenic activities over recent decades, such as the burning of fossil fuels and fertilizer application, have resulted in a rapid increase in reactive $\mathrm{N}$ emissions and atmospheric $\mathrm{N}$ deposition on a global scale (Dentener et al., 2006; Galloway et al., 2008). Currently, the intensity of atmospheric $\mathrm{N}$ deposition in China is considered to equal or even exceed the intensity in Europe and America, causing concern among governments and the public over this important ecological and environmental problem. Some studies have demonstrated that atmospheric $\mathrm{N}$ deposition in China increased rapidly over recent decades, and have predicted that, as this increase was primarily caused by increased energy consumption and $\mathrm{N}$ fertilizer use, this increasing trend will continue in the future with the continuing development of China's economy (Jia et al., 2014; Lü and Tian, 2007; Liu et al., 2013; Zhang et al., 2012).

Zhu et al. (2015), for the first time, demonstrated the composition of the wet $\mathrm{N}$ deposition through rainfall events in China from site to national scales, in view of ammonium $\left(\mathrm{NH}_{4}^{+}-\mathrm{N}\right)$, and nitrate $\left(\mathrm{NO}_{3}^{-}-\mathrm{N}\right)$, total dissolved $\mathrm{N}(\mathrm{TDN})$, total particulate N (TPN), and total N (TN). The discussion in Liu et al. (in this issue) speculates that Zhu et al. (2015) may have underestimated DON but overestimated TPN in wet deposition in China, owing to the uncertainty resulting from the sampling, storage, and analysis methods.

\footnotetext{
* Corresponding author.

E-mail address: henp@igsnrr.ac.cn (N. He).
}

We appreciate the comments of Liu et al. (in this issue) on our manuscript (Zhu et al., 2015), which have helped us to make some improvements to subsequent related studies. However, we disagree with their interpretation on some points. Firstly, the difficulties in quality control from sampling to analyzing are common to all studies regarding atmospheric DON deposition, including the studies cited by Liu et al. (in this issue). More importantly, their discussion did not fully consider the apparent influence of different scaling-up methods (from an observation site scale to a national scale) on estimations of atmospheric $\mathrm{N}$ deposition in China. Our response and other primary considerations are set out in the following four sections.

\section{Concepts and monitoring procedures for atmospheric $\mathbf{N}$ deposition must be addressed systematically}

The lack of an optimal standard for concepts and sampling procedures of atmospheric $\mathrm{N}$ deposition results in incomparable results from different studies, and increases the difficulties associated with data integration. For example, Zhu et al. (2015) reported data as wet deposition through rainfall events rather than bulk deposition as discussed by Liu et al. (in this issue), because samples were only collected during rainfall events. In practice, precipitation samples were collected monthly 3-5 times during rainfall events from the onset of rain (or snow) to the end by artificially setting up the plastic buckets at the height of $1.5 \mathrm{~m}$ above the ground. The samples were collected immediately after each rainfall event, and then stored in polyethylene plastic bottles below $-20^{\circ} \mathrm{C}$. There are two commonly used effective approaches to prevent $\mathrm{N}$ degradation by microorganisms during the sampling of atmospheric $\mathrm{N}$ 
deposition: immediate freezing at temperatures below $-20{ }^{\circ} \mathrm{C}$ (Zhu et al., 2015) and adding $1 \mathrm{ml} \mathrm{CHCl}$ per liter of sample (Zhang et al., 2012). We adopted an artificial collecting procedure of rainfall samples and the immediate freezing method as the optimum methods to combine with the artificial meteorological monitoring and atmospheric wet $\mathrm{N}$ deposition monitoring at 41 field stations from the Chinese Ecosystem Research Network (CERN) (Fu et al., 2010). This network is the largest network integrating ecological monitoring, research, and demonstrations in the world, and sampling processes and storage methods can therefore be implemented as standard procedures using the available first-class facilities and experienced observers. Atmospheric particulate matter and aerosols are rained out over the duration of a rainfall event. However, previous studies focused on total dissolved $\mathrm{N}$ (TDN) in rainwater through filtering the mixed rainwater to obtain the dissolved fraction. With the rapid industrialization and urbanization of China, TPN in rainfall is expected to increase rapidly and should not be ignored. Unfortunately, the deposition of TPN through rainfall events is not considered in the studies cited by Liu et al. (in this issue) which focus on dry deposition or traditional wet deposition.

\section{Apparent differences in DON results from the analysis method (or quality control) as well as statistical methods}

DON cannot be measured directly, which makes quality control a critical consideration during the entire processes of sampling, storage, and analysis in all studies (Jickells et al., 2013; Zhang et al., 2012). It is necessary to note that the persulfate oxidation digestion and ultraviolet methods have been widely used, therefore the influences of method on the results should be accepted. However, there are apparent differences in the estimation of TDN deposition in China among different studies, such as 0.51 (Zhu et al., 2015), 4.84 (Du and Liu, 2014), and $6.84 \mathrm{~kg} \mathrm{~N} \mathrm{ha}^{-1}$ year $^{-1}$ (Zhang et al., 2012) in China.
Therefore, it is necessary to reconsider and emphasize quality control for DON deposition studies when comparing or integrating existing studies. The apparent differences can be largely explained as follows. Firstly, the trade-off between DON and TPN through rainfall events may cause uncertainties. Zhu et al. (2015) used a $0.45 \mu \mathrm{m}$ membrane to divide insoluble particulate matter before the concentrations of $\mathrm{TDN}, \mathrm{NH}_{4}^{+}-\mathrm{N}$, and $\mathrm{NO}_{3}^{-}-\mathrm{N}$ were measured using a continuous flow analyzer. This implies that DON in their study included DON and $<0.45 \mu \mathrm{m}$ particulate organic $\mathrm{N}$ and TPN, including insoluble $\mathrm{N}$ and organic $\mathrm{N}$ absorbed by particles larger than $0.45 \mu \mathrm{m}$. Therefore, the observed DON should be to some extent underestimated. Secondly, the roles of filter membranes should be emphasized in future studies, as they directly influence the division of DON and TPN in wet N deposition. Thirdly, it is also necessary to point out that DON should vary significantly among different observation sites owing to the highly variable levels of development in different regions of China (Fig. 1). In detail, Zhu et al. (2015) estimated annual DON and TDN deposition as 5.99 and $32.49 \mathrm{~kg} \mathrm{~N} \mathrm{ha}^{-1}$ year $^{-1}, 4.71$ and $23.41 \mathrm{~kg} \mathrm{~N} \mathrm{ha}^{-1}$ year $^{-1}$, and 7.71 and $45.24 \mathrm{~kg} \mathrm{~N} \mathrm{ha}^{-1}$ year $^{-1}$ in Shenyang, Duolun, and Changshu, respectively. DON accounted for $18 \%, 20 \%$, and $17 \%$ of TDN in each of the three stations, respectively, which is consistent with previous studies (Du and Liu, 2014; Zhang et al., 2012). Furthermore, if we simply take an average value of atmospheric $\mathrm{N}$ deposition, as in Du and Liu (2014) and Zhang et al. (2012), the estimation of DON would be $0.96 \mathrm{~kg} \mathrm{~N} \mathrm{ha}^{-1}$ year $^{-1}$, and if we further neglect the negative values, the average would be $1.45 \mathrm{~kg} \mathrm{~N} \mathrm{ha}^{-1}$ year $^{-1}$. Du and Liu (2014) estimated that DON values were $7.34 \pm 2.16,4.68 \pm 2.78$, and $3.05 \pm$ 1.71 in urban ( 7 sites), rural ( 20 sites), and remote ( 8 sites) regions, respectively. Conversely, numbers of these sites were 1,14 , and 26 in the study by Zhu et al. (2015). Fourthly, differences in statistical scales (or sample size) and scaling-up methods are likely to represent the most important influence on uncertainty under the conditions of insufficient and uneven spatial distribution of observation sites (see the next

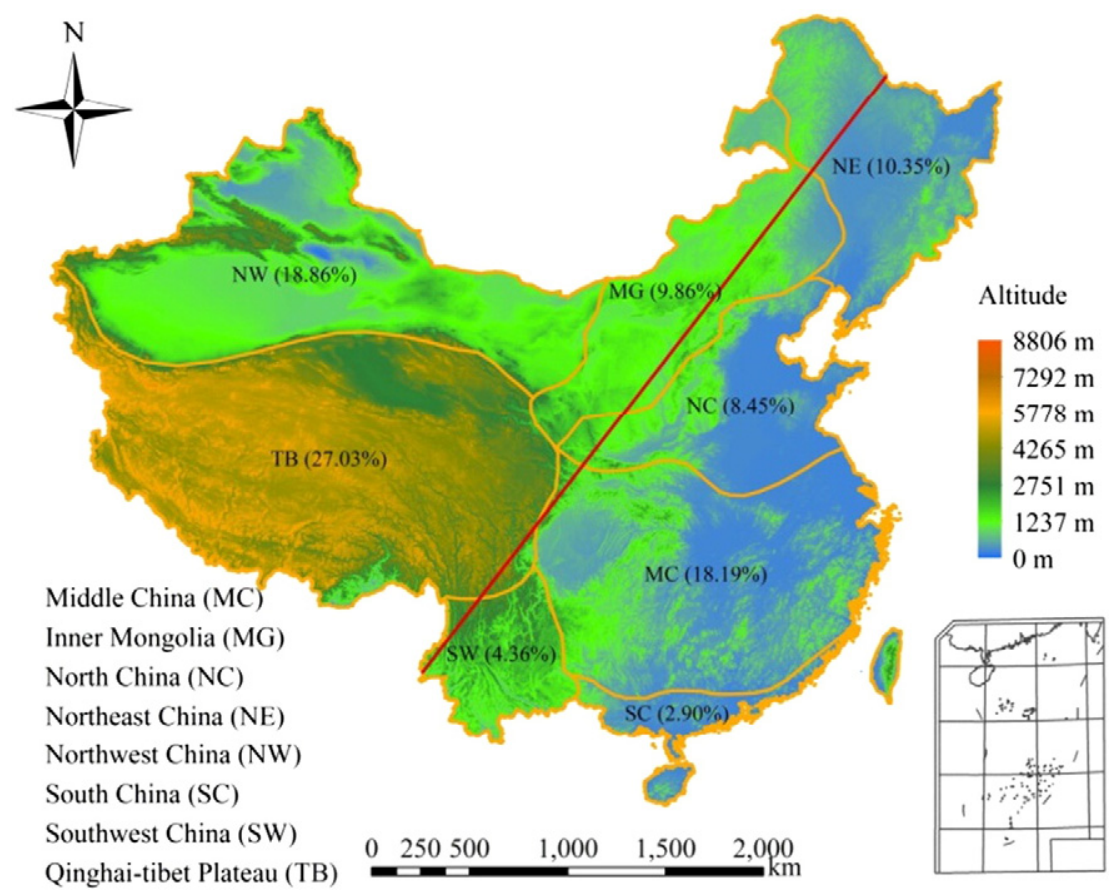

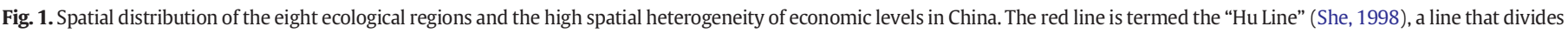

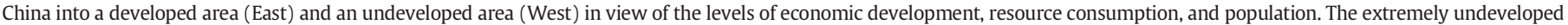

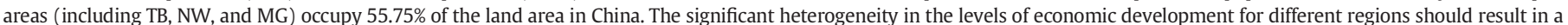

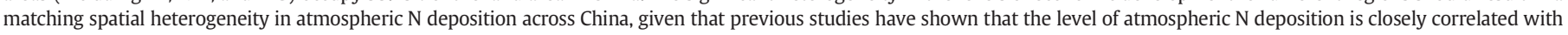
energy consumption and N fertilizer use (Jia et al., 2014; Zhu et al., 2015). 
section for details), considering the spatial pattern of China's eight ecological regions and the high spatial heterogeneity of economic levels in China (Fig. 1).

\section{Selection of the scaling-up method should be emphasized when estimating atmospheric $\mathrm{N}$ deposition in China at a national scale}

Commonly, there are three approaches to scaling-up observation data from site to national scale: modeling methods (Gao et al., 2014), geostatistical methods (Kriging interpolation) (Jia et al., 2014; Lü and Tian, 2007; Zhu et al., 2015), and averaging methods (Du and Liu, 2014; Liu et al., 2013; Zhang et al., 2012). Theoretically, the results of these three methods should be reasonably consistent, provided that atmospheric $\mathrm{N}$ deposition is homogeneous across the different regions of China; in other words, provided that the levels of economic development are relatively balanced in different regions, atmospheric $\mathrm{N}$ deposition is dependent on energy consumption and $\mathrm{N}$ fertilizer use (Jia et al., 2014; Lü and Tian, 2007; Liu et al., 2013; Zhang et al., 2012). However, the economic development of different regions varies significantly, which should therefore result in considerable spatial heterogeneity in atmospheric $\mathrm{N}$ deposition across China. For example, extremely undeveloped areas (including Qinghai-Tibet Plateau (TB), Inner Mongolia (MG), and northwest China (NW)) occupy 55.75\% of China's land area, and had a gross domestic product (GDP) of only $8.4 \%$ in 2014 (Fig. 1). Therefore, we can infer that atmospheric $\mathrm{N}$ deposition is low in these regions owing to undeveloped agriculture and industry, and data from previous studies has confirmed this hypothesis (Lü and Tian, 2007; Liu et al., 2013; Jia et al., 2014; Zhu et al., 2015). As a result, methods that consider the corresponding area around observation sites (or the level of development in the area surrounding an observation site), such as modeling methods and Kriging interpolation, should produce more accurate results than averaging methods when scaling-up from observation site data to a national scale across China, as long as researchers can obtain data from a sufficient number of observation sites that are distributed evenly across China. Furthermore, researchers should be cautious of directly copying the scaling-up methods used for Europe and America, owing to the differences in the homogeneity of economic development in different regions.

\section{Different scaling-up methods may be the main reason for high uncertainty in estimations of atmospheric $\mathrm{N}$ deposition in China at a national scale}

Different scaling-up methods result in apparent differences in the estimation of atmospheric $\mathrm{N}$ deposition in China. For example, if we carefully check the details of two previous studies, Liu et al. (2013) and Jia et al. (2014), we find that they used similar datasets that were both derived from publicly published data on atmospheric $\mathrm{N}$ deposition in China. The estimation of atmospheric dissolved inorganic nitrogen (DIN) deposition in China (at a national scale) is about $21.1 \mathrm{~kg} \mathrm{~N} \mathrm{ha}^{-1}$ year $^{-1}$ in the former study (Liu et al., 2013, averaging method) and $13.87 \mathrm{~kg} \mathrm{~N} \mathrm{ha}^{-1}$ year $^{-1}$ in the latter (Jia et al., 2014, Kriging interpolation over about 280 sites). In Zhu et al. (2015), we reported an estimate of DIN of approximately $13.18 \mathrm{~kg} \mathrm{~N} \mathrm{ha}^{-1}$ year $^{-1}$ based on 41 observation stations using Kriging interpolation, which is comparable with the results of Jia et al. (2014). In other words, these two studies arrived at similar estimations of DIN based on two independent datasets, 280 sites in Jia et al. (2014) and 41 sites in Zhu et al. (2015), using the Kriging interpolation method. In fact, most of the monitoring sites used in these published papers in China were distributed in developed areas (Fig. 1), which cover a disproportionately small fraction of China. Therefore, we assumed that a simple averaging method would overestimate atmospheric $\mathrm{N}$ deposition at a national scale, because no consideration would be given to the lack of observation sites in undeveloped regions, despite their predominance across China. In summary, the effects of the scaling-up method on nationalscale results require further study, and the observation network for atmospheric $\mathrm{N}$ deposition needs to be strengthened to decrease the uncertainty, especially in the TB, IM, and NW regions.

In conclusion, there are large uncertainties in the estimation of atmospheric $\mathrm{N}$ deposition in China, which result from different concepts, sampling procedures, analysis methods, and scaling-up methods. The following recommendations are made in view of the challenges discussed in this paper.

1) A systemic observation network at a national scale should be established to conduct long-term monitoring of atmospheric $\mathrm{N}$ deposition (including dry and wet deposition), based on the existing ecological stations administered by different departments in China. Such a network is required to explore the composition, dynamics, and spatial patterns of atmospheric $\mathrm{N}$ deposition.

2) Standard procedures for sampling, storage, and analysis in studies of atmospheric $\mathrm{N}$ deposition should be discussed and agreed on between experts, to enhance the consistency or comparability of different studies.

3) More observation sites should be established in typical terrestrial ecosystems (e.g., forests, grasslands, and deserts), especially in the $\mathrm{TB}$, IM and NW regions, to enhance the representation of observation sites.

4) Studies of scaling-up methods should be a priority in the future to enhance the accuracy of atmospheric $\mathrm{N}$ deposition estimations in China, especially as a more even distribution of observation sites in different regions cannot be expected in the foreseeable future.

5) Combinations of modeling methods, field control experiments, and survey data should be investigated to explore the influence of atmospheric $\mathrm{N}$ deposition on the structure and functions of terrestrial ecosystems.

\section{References}

Dentener, F., Drevet, J., Lamarque, J.F., Bey, I., Eickhout, B., Fiore, A.M., et al., 2006. Nitrogen and sulfur deposition on regional and global scales: a multimodel evaluation. Glob. Biogeochem. Cycles 20, GB4003.

Du, E.Z., Liu, X.J., 2014. High rates of wet nitrogen deposition in China: a synthesis. In: Sutton, M.A., Mason, K.E., Sheppard, L.J., Sverdrup, H., Haeuber, R., Hicks, W.K. (Eds.), Nitrogen Deposition, Critical Loads and Biodiversity. Springer, Netherlands, pp. 49-56.

Fu, B.J., Li, S.G., Yu, X.B., Yang, P., Yu, G.R., Feng, R.G., et al., 2010. Chinese ecosystem research network: progress and perspectives. Ecol. Complex. 7, 225-233.

Galloway, J.N., Dentener, F.J., Capone, D.G., Boyer, E.W., Howarth, R.W., Seitzinger, S.P., et al. 2004. Nitrogen cycles: past, present, and future. Biogeochemistry 70, 153-226.

Galloway, J.N., Townsend, A.R., Erisman, J.W., Bekunda, M., Cai, Z.C., Freney, J.R., et al., 2008. Transformation of the nitrogen cycle: recent trends, questions, and potential solutions. Science 320, 889-892.

Gao, Y., Zhu, X.J., Yu, G.R., He, N.P., Wang, Q.F., Tiang, J., 2014. Water use efficiency threshold for terrestrial ecosystem carbon sequestration in China under afforestation. Agric. For. Meteorol. 195, 32-37.

Jia, Y.L., Yu, G.R., He, N.P., Zhan, X.Y., Fang, H.J., Sheng, W.P., et al., 2014. Spatial and decadal variations in inorganic nitrogen wet deposition in China induced by human activity. Sci. Rep. 4, 3763. http://dx.doi.org/10.1038/srep03763.

Jickells, T., Baker, A.R., Cape, J.N., Cornell, S.E., Nemitz, E., 2013. The cycling of organic nitrogen through the atmosphere. Philos. Trans. R. Soc. B Biol. Sci. 368, 91-97.

Liu, X.J., Zhang, Y., Han, W.X., Tang, A.H., Shen, J.L., Cui, Z.L., et al., 2013. Enhanced nitrogen deposition over China. Nature 494, 459-462.

Liu, X.J., Xu, W., Pan, Y.P., Du, E.Z., 2015. Liu et al. suspect that Zhu et al. (2015) may have underestimated dissolved organic $\mathrm{N}$ but overestimated total particulate $\mathrm{N}$ in wet deposition in China. Sci. Total Environ. 520, 300-301.

Lü, C.Q., Tian, H.Q., 2007. Spatial and temporal patterns of nitrogen deposition in China: synthesis of observational data. J. Geophys. Res. Atmos. 112, D22.

She, W., 1998. Hu Huanyong: father of China's population geography. China Popul. Today $15,1-20$.

Zhang, Y., Song, L., Liu, X.J., Li, W.Q., Lü, S.H., Zheng, L.X., et al., 2012. Atmospheric organic nitrogen deposition in China. Atmos. Environ. 46, 195-204.

Zhu, J.X., He, N.P., Wang, Q.F., Yuan, G.F., Wen, D., Yu, G.R., et al., 2015. The composition, spatial patterns, and influencing factors of atmospheric wet nitrogen deposition in Chinese terrestrial ecosystems. Sci. Total Environ. 511, 777-785. 